\title{
Pathological responses after angiogenesis or EGFR inhibitors in metastatic colorectal cancer depend on the chemotherapy backbone
}

\begin{abstract}
J Carrasco*, ${ }^{*}$, M Gizzi ${ }^{1}$, G Pairet ${ }^{2}$, V Lannoy ${ }^{3}$, P Lefesvre ${ }^{4}$, J-F Gigot ${ }^{5}$, C Hubert ${ }^{5}$, A Jouret-Mourin ${ }^{2}$, Y Humblet ${ }^{3}$, J-L Canon ${ }^{1}$, C Sempoux ${ }^{2}$, X Chapaux $^{6}$, E Danse $^{7}$, N Tinton $^{8}$, B Navez $^{5}$ and M Van den Eynde ${ }^{3}$ ${ }^{1}$ Department of Medical Oncology, Grand Hôpital de Charleroi (GHdC), Grand rue 3, 6000 Charleroi, Belgium; ${ }^{2}$ Department of Pathology, Cliniques Universitaires St-Luc/Université Catholique de Louvain (UCL), Avenue Hippocrate 10, 1200 Brussels, Belgium; ${ }^{3}$ Department of Medical Oncology, Cliniques Universitaires St-Luc/Université Catholique de Louvain (UCL), Avenue Hippocrate 10, 1200 Brussels, Belgium; ${ }^{4}$ Department of Molecular Pathology, Institut de Pathologie et de Génétique (IPG), Avenue Georges Lemaître 25, 6041 Gosselies, Belgium; ${ }^{5}$ Department of Abdominal Surgery and Transplantation, Cliniques Universitaires St-LuC/ Université Catholique de Louvain (UCL), Avenue Hippocrate 10, 1200 Brussels, Belgium; ${ }^{6}$ Department of Radiolgy, Grand Hôpital de Charleroi (GHdC), Grand rue 3, 6000 Charleroi, Belgium; ${ }^{7}$ Department of Radiology, Cliniques Universitaires St-Luc/Université Catholique de Louvain (UCL), Avenue Hippocrate 10, 1200 Brussels, Belgium and ${ }^{8}$ Department of Abdominal Surgery, Grand Hôpital de Charleroi (GHdC), Grand rue 3, 6000 Charleroi, Belgium
\end{abstract}

Background: Optimal preoperative treatment before colorectal cancer metastases (CRCM) resection remains unclear. This study evaluated pathological responses (pR) in CRCM resected after chemotherapy alone or combined with angiogenesis or epidermal growth factor receptor (EGFR) inhibitors.

Methods: Pathological response was retrospectively evaluated on 264 resected metastases from 99 patients. The proportion of responding metastases after different preoperative treatments was reported and compared. Patient's progression-free survival (PFS) and overall survival (OS) were compared based on $\mathrm{pR}$.

Results: The combination of anti-angiogenics with oxaliplatin-based chemotherapy resulted in more $p R$ than when they were combined with irinotecan-based chemotherapy ( $80 \%$ vs $50 \% ; P<0.001)$. Inversely, the combination of EGFR inhibitors with oxaliplatin-based chemotherapy seemed to induce fewer pR than when they were combined with irinotecan-based treatment (53\% vs 72\%; $P=0.049$ ). Overall survival at 5 years was improved for patients with a pR in all resected metastases compared with those who did not achieve a pR $(68.5 \%$ vs $32.6 \% ; P=0.023)$ and this response was the only factor predicting OS in a multivariate analysis.

Conclusion: The chemotherapy partner combined with angiogenesis or EGFR inhibitors influenced pR in resected CRCM. In our exploratory analysis anti-angiogenic/oxaliplatin-based regimens and anti-EGFR/irinotecan-based regimens were associated with the highest $\mathrm{pR}$. Prospective randomised trials should be performed to validate these observations.

*Correspondence: Dr J Carrasco; E-mail: javier.carrasco@ghdc.be

Received 16 August 2014; revised 25 July 2015; accepted 12 August 2015; published online 13 October 2015

(c) 2015 Cancer Research UK. All rights reserved 0007-0920/15 
Colorectal cancer is the second cause of cancer death in the Western World. Up to $50 \%$ of patients will develop metastatic disease and only $5 \%$ of these will survive more than 5 years (Edge et al, 2010). Currently, oxaliplatin and/or irinotecan-based regimens, in combination with angiogenesis or epidermal growth factor receptor (EGFR) inhibitors, are mainstay treatments in the metastatic setting. It is not clearly established whether one combination is superior to another and the optimal sequencing of consecutive therapeutic lines is under study (Chibaudel et al, 2014; Schwartzberg et al, 2014; Heinemann et al, 2014b).

Surgical resection of liver colorectal cancer metastases (CRCM) can improve patient outcomes with encouraging survival rates reaching 58\% at 5 years (Abdalla et al, 2004). Administration of preoperative systemic treatment before metastases resection is frequently used to increase the rate of curative resection (Adam et al, 2004a). Moreover, preoperative chemotherapy allows the identification of non-responders for whom surgery may be contraindicated (Allen et al, 2003; Adam et al, 2004b).

Several studies have shown that pathological response $(\mathrm{pR})$ to preoperative treatment before liver CRCM resection strongly influences prognosis. Rubbia-Brandt et al (2007) reported a correlation between $\mathrm{pR}$ on resected metastases and overall survival (OS). Blazer et al (2008) confirmed these observations and revealed that $\mathrm{pR}$ on resected liver CRCM were improved when the preoperative chemotherapy was combined with bevacizumab. However, optimal preoperative treatment combinations before CRCM resection are still unclear. In this retrospective study, we explored this issue by comparing the rate of $\mathrm{pR}$ observed on CRCM resected after different chemotherapy regimens with or without anti-angiogenic or anti-EGFR targeted therapies (TT).

\section{MATERIALS AND METHODS}

Patients. This retrospective study was performed at Grand Hôpital de Charleroi and Cliniques Universitaires Saint-Luc (Belgium). Ninety-nine patients with colorectal adenocarcinoma with liver and lung metastases were included. All underwent surgical resection with a curative intent of their CRCM after preoperative treatment between 2003 and 2011 (Table 1). Patients preoperatively treated with regimens that did not contain oxaliplatin or irinotecan, or those who received concomitant or consecutive oxaliplatin and irinotecan-based regimens, were not eligible. In case of metachronous CRCM for patients having received previous systemic treatment, a minimum of 6 months disease-free period without chemotherapy was required for inclusion in this study. Previous use of TT (anti-VEGF or antiEGFR) was not allowed. Progression-free survival (PFS) was calculated from the start of preoperative treatment to the date of disease progression or to the latest follow-up visit. Overall survival was calculated from the same initial time point and death. The study was approved by local ethical committees and conducted in accordance with the Helsinki Declaration of the World Medical Association. Considering the non-interventional retrospective design, patient's informed consent was not required.

Pathological response assessment. Pathological evaluation was performed on hematoxylin and eosin stained slides from formalinfixed paraffin-embedded $0.5 \mathrm{~mm}$ sections of 264 metastases. All slides were examined by two independent pathologists. Pathological response was scored for each CRCM according to the methodology and classification proposed by Rubbia-Brandt et al (2007) for liver metastases. This scoring identifies five tumour regression grades (TRG) based on the presence of residual tumour cells and the extent of fibrosis. By analogy with tumour response evaluation based on imagery and to improve the clinical relevance of $\mathrm{pR}$ assessment, we grouped the five TRG scores into three categories: (1) no pR corresponded to TRG 5 or 4 as confirmed by the TRG evaluation on a control group of patients whose metastases were resected without preoperative treatment (Supplementary Figure 1), (2) minor pR (TRG 3), and (3) major or complete $\mathrm{pR}$ (TRG 2 or TRG 1). Pathological responses were analysed at two levels: (1) the metastasis-related analysis considered TRG of each individual metastasis and, (2) the patient-related analysis considered all metastases from one patient and retained the worse pR (highest TRG) to determine the patients' pR status.

Radiological response assessment. Computerised tomography (CT) or magnetic resonance imaging (MRI) procedures were available for 90 of the 99 preoperatively treated patients. Responses to preoperative treatment were evaluated according to response evaluation criteria in solid tumours (RECIST) version 1.1 and defined as complete response (CR), partial response (PR), stable disease (SD) and progressive disease (Eisenhauer et al, 2009). Initial radiographies before preoperative treatment were compared with those obtained at the end of treatment, before surgery, with a maximum delay of 3 months from the last chemotherapy administration.

Serum carcinoembryonic antigen (CEA) monitoring. Serum CEA values during preoperative treatment were available for 68 of the 99 included patients. Initial values before preoperative treatment were compared with those obtained during or at the end of treatment, before surgery, with a maximum delay of 3 months from the last chemotherapy administration.

Statistics. Multiple Kruskal-Wallis or Mann-Whitney tests were used to compare TRG distribution among the resected metastases. Overall survival and PFS were estimated using the Kaplan-Meier method and compared using the Log-rank test. A two-tailed $P$-value of $<0.05$ was considered statistically significant. An uni- and multi-variate Cox regression analysis of factors potentially associated with OS was also performed. SAS version 9.3 software (SAS Institute Inc., Cary, NC, USA) and UCLA Statistics Online Computational Resource (www.socr.ucla.edu/SOCR.html) were used for statistical analyses.

\section{RESULTS}

Cohort overview. Patients distribution and characteristics according to preoperative management is reported in Table 1. All preoperative treatments were either oxaliplatin or irinotecanbased chemotherapy. Fifty-eight patients received combinations with an anti-angiogenic (bevacizumab, $n=41$; cediranib, $n=2$ ) or an anti-EGFR TT (cetuximab, $n=11$; panitumumab, $n=4$ ). All patients treated with anti-EGFR TT had no KRAS exon 2 mutations. Overall, the predominant preoperative treatment was FOLFIRI plus bevacizumab. There was disparity concerning the number of cycles administered preoperatively (range 1-19), and considerable heterogeneity with regard to the number of resected metastases per patient (1-20).

\section{Preoperative treatment response evaluation}

Pathological response assessment. Two hundred and sixty-four resected metastases from 99 preoperatively treated patients were reviewed. Ninety-seven per cent of all metastases were from the liver. Each metastasis was classified according to the TRG categories (Figure 1A).

In patients with multiple metastases, heterogeneous responses were observed after preoperative treatment. Among the 56 patients with $>1$ metastasis, 17 (30\%) had heterogeneous TRG scores that varied by more than two grades from one metastasis to another (Figure 1B). Therefore, the influence of different preoperative treatments on $\mathrm{pR}$ was compared by a metastasis-related analysis at the metastasis level (Figure 1C). 
Table 1. Patient disease and treatment characteristics according to preoperative treatment

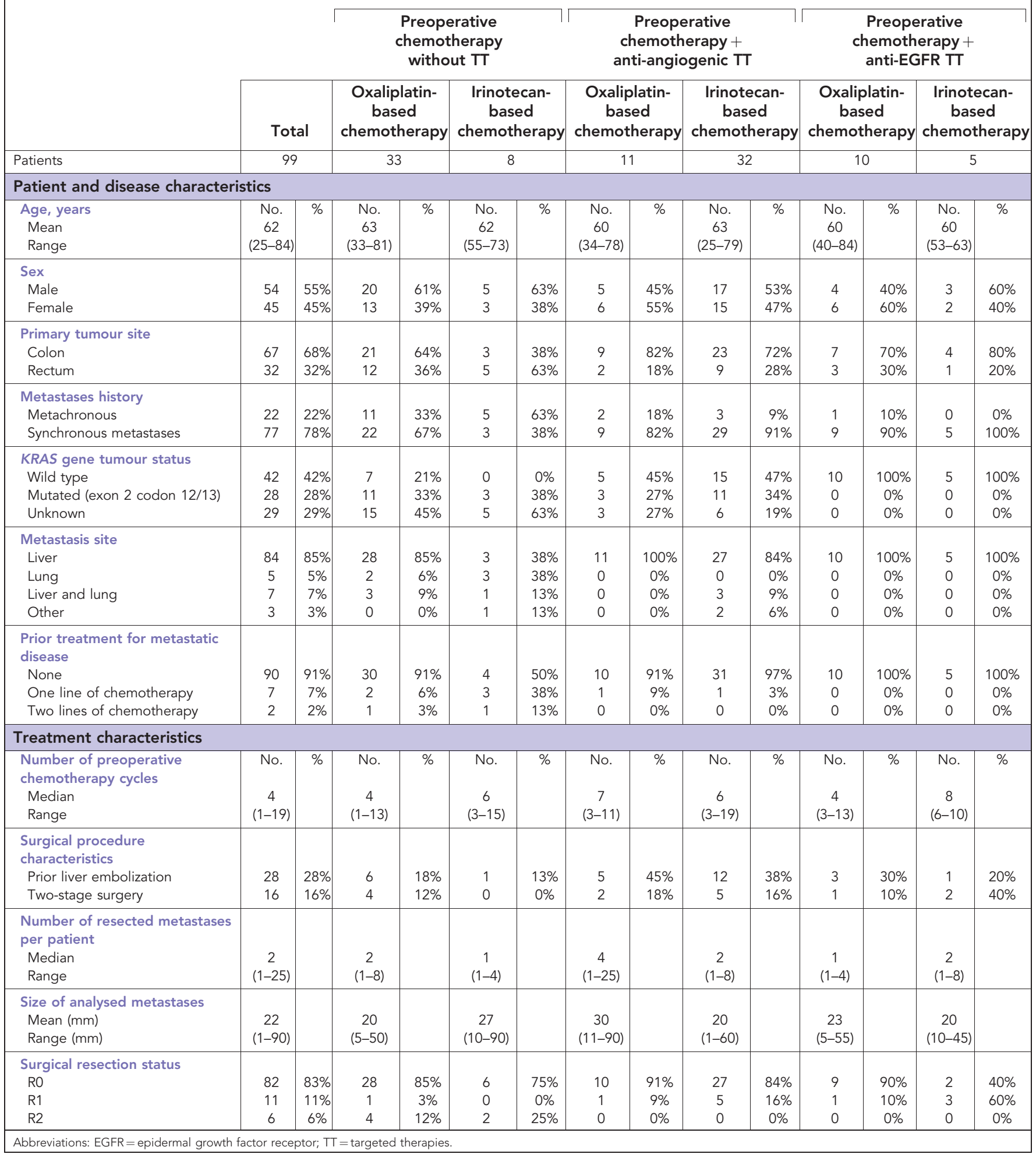

After any preoperative treatment, $56 \%$ of the metastases achieved a $\mathrm{pR}$ and $30 \%$ of these involved a major or complete $\mathrm{pR}$ (data not shown). Overall, the addition of an anti-angiogenic or an anti-EGFR TT to a preoperative chemotherapy induced similar $\mathrm{pR}$ rates $(62 \%$ and $63 \%$, respectively). This $\mathrm{pR}$ rates tended to be higher to those observed after chemotherapy alone but significance was not reached $(62 \%, 63 \%$ vs $45 \%$; $P=0.059$; Figure 1C).
An analysis distinguishing the chemotherapy backbone combined to the TT revealed that the addition of an anti-angiogenic to the oxaliplatin chemotherapy backbone was associated with a $\mathrm{pR}$ rate of $80 \%$ vs $48 \%$ for the same treatment without the the TT $(P<0.001$; Figure 1C). The addition of an anti-angiogenic to the irinotecan chemotherapy backbone increased the $\mathrm{pR}$ compared with the same treatment without the TT, but the difference was not significant (50\% vs 27\%; $P=0.132$ ). Overall, a higher $\mathrm{pR}$ rate was obtained 
A

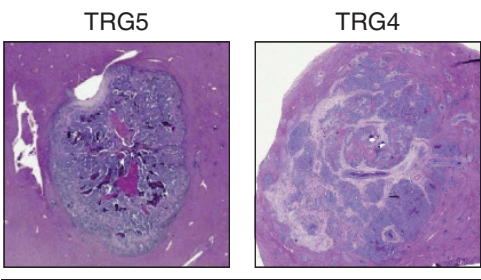

No response
TRG3

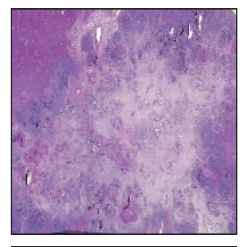

Minor response
TRG2

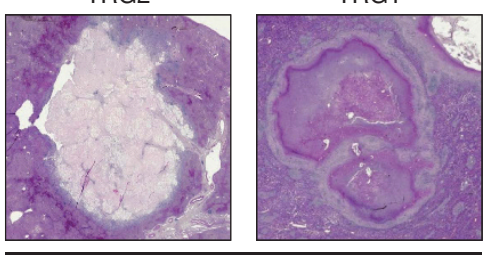

Major response

B

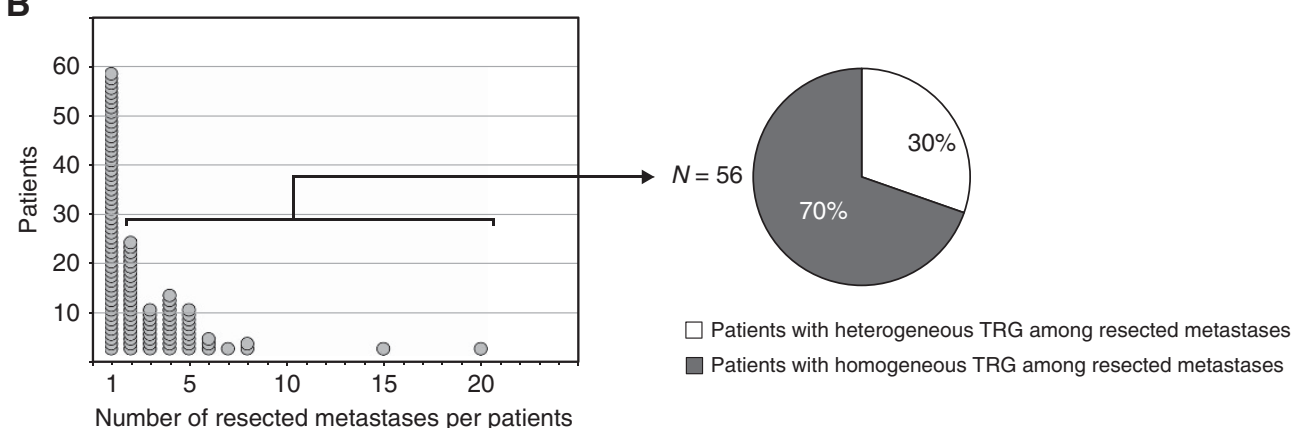

C Distribution of pathological responses ( $N=$ number of metastases)

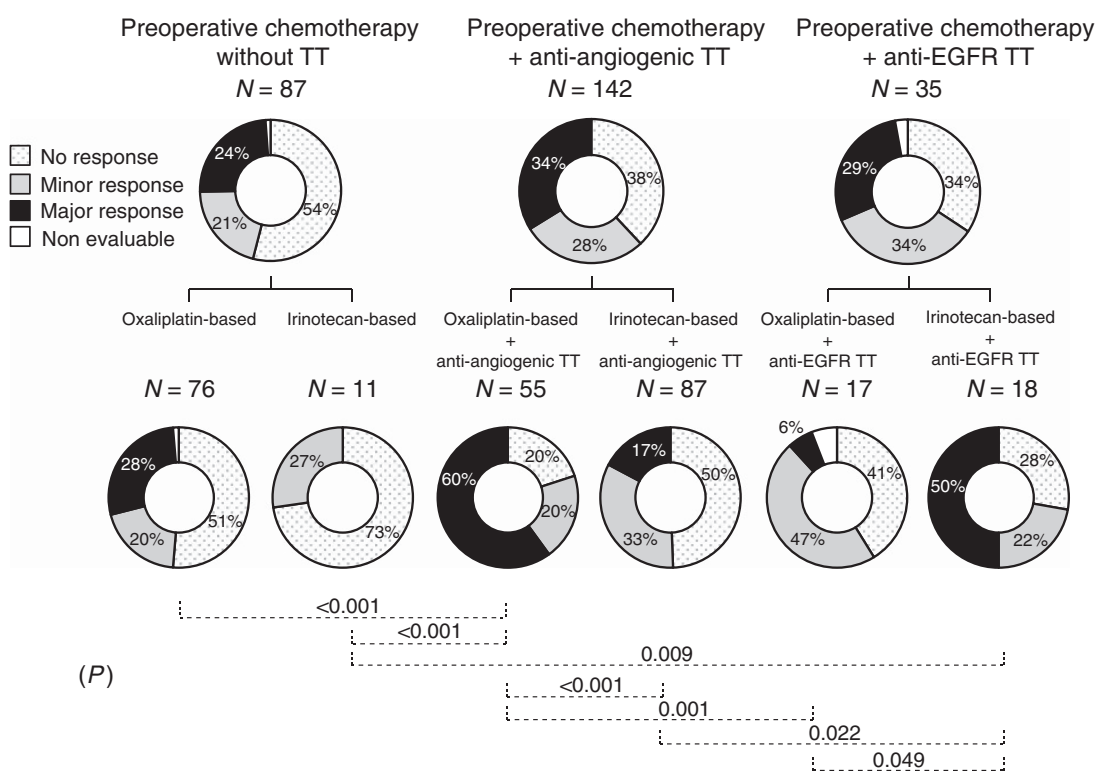

Figure 1. Distribution of pathological responses in resected metastases. (A) Pathological response was evaluated according to the TRG score ranking digressively the importance of the response from 5 to 1 based on the amount of viable cells, necrotic zones and tumoural fibrosis. Representative images corresponding to each grade are shown. Tumour regression grades 5 and 4 correspond to an absence of response, TRG 3 to a minor response and TRG 2 and 1 to major responses. (B) For the 56 patients having multiple resected metastases, heterogeneous TRG scores of more than 2 grades disparity among their different metastases were found in $30 \%$ of the cases. (C) Pathological response was evaluated in 264 available metastases resected from 99 patients after preoperative treatment, and pR distribution was reported for each administered treatment. Significant pairwise comparisons between the various regimens are noted $(P)$.

when the anti-angiogenic was combined with an oxaliplatin $v s$ an irinotecan chemotherapy backbone $(80 \%$ vs $50 \%$; $P<0.001)$.

Similar analysis revealed that the addition of an anti-EGFR to the oxaliplatin chemotherapy backbone did not significantly increase the $\mathrm{pR}$ rate compared with the same chemotherapy administered alone (53\% vs $48 \% P=0.778$; Figure $1 \mathrm{C}$ ). When the anti-EGFR was combined with the irinotecan chemotherapy backbone, the $\mathrm{pR}$ rate was significantly increase related to the same treatment without the TT ( $72 \%$ vs $27 \% P=0.009)$. Overall, a higher rate of $\mathrm{pR}$ was obtained when the anti-EGFR was combined with an irinotecan $v s$ an oxaliplatin chemotherapy backbone, but difference was weakly significant $(72 \%$ vs $53 \% ; P=0.049)$.
Concordances between $p R$, imagery and CEA variations. To compare observed $\mathrm{pR}$ on resected CRCM with other approaches based on imagery and blood tumour biomarkers, evaluating tumour responses at the patient level, a patient-related analysis of $\mathrm{pR}$ was preformed. For each patient, a pR status was determined based on the worse TRG grade among all their resected metastases. Patients having a $\mathrm{pR}$ status $\leqslant 3$ were considered responders (major or minor responses) and all others were deemed non-responders.

This analysis revealed that $51 \%$ of patients who had a PR or CR based on RECIST criteria (evaluated on CT scan or MRI) were considered as non-responders based on their $\mathrm{pR}$ status, and $47 \%$ of patients with radiologically SD responded based on 
their $\mathrm{pR}$ status (Figure 2A). If the analysis was restricted to patients followed by MRI, only $35 \%$ of those having a RECIST response were considered as non-responders by the pathological approach, and $27 \%$ of those having a RECIST SD were responders based on their pR status. Serum CEA assessment revealed that among patients whose CEA decreased during preoperative treatment $38 \%$ were non-responders according to their $\mathrm{pR}$ status, and $13 \%$ of those with a stable or increasing CEA had a responder $\mathrm{pR}$ status (Figure 2B).

Pathological responses and OS. The influence of the patient's $p R$ status on disease evolution was evaluated for the 99 included patients. Our analysis clearly revealed that patients who achieved a minor or major $\mathrm{pR}$ had an improved OS: $68 \%$ of patients with a responder $\mathrm{pR}$ status were alive 5 years after treatment onset $v s 33 \%$ for non-responder patients $(P=0.02$; Figure $3 \mathrm{~A})$. Progression-free survival was not significantly different between those two groups with $71 \%$ of patients with a responder $\mathrm{pR}$ status progressing after 5 years $v s 86 \%$ for non-responder patients $(P=0.26$; Figure $3 \mathrm{~B})$.

To identify factors associated with OS, we performed univariate and multivariate analyses (Table 2). The univariate analysis revealed that patient's $\mathrm{pR}$ status was the strongest predictor of OS $(P<0.01)$. Macroscopic incomplete metastases resection (R2) and preoperative residual CEA serum level were also predictive of OS $(P=0.01)$. Microscopic incomplete resection (R1) or RECIST responses were not predictive of OS. The only parameter that was predictive of OS following multivariate analysis was the patient's pR status (Table 2).

\section{DISCUSSION}

The use of perioperative chemotherapy in $\mathrm{mCRC}$ patients engaged in a liver metastases resection strategy is a source of debate. FOLFOX is the only regimen evaluated in a randomised trial $v s$ surgery alone, offering a modest improvement in PFS (Nordlinger et al, 2008, 2013).

In this retrospective analysis, we observed a higher proportion of $\mathrm{pR}$ when bevacizumab was combined with oxaliplatin-based regimens but not when it was given with irinotecan. Our findings support those of Blazer and colleagues who observed higher rates of major $\mathrm{pR}$ on resected liver metastases when bevacizumab was combined with FOLFOX preoperatively vs FOLFOX alone (54\% vs $32 \%$, respectively), and minor differences when bevacizumab was combined with FOLFIRI vs FOLFIRI alone (30\% vs 26\%, respectively) (Blazer et al, 2008).

Radiological response rates reported after cetuximab combined with chemotherapy are higher than those observed after combination with bevazicumab (Heinemann et al, 2014a). Nevertheless, this difference was not confirmed at the pathological level by recent publications (Pietrantonio et al, 2015; Stremitzer et al, 2015). In accord with these publications, we did not observed differences on the $\mathrm{pR}$ rate after combination of preoperative chemotherapies with anti-angiogenic or anti-EGFR TT. A further analysis distinguishing the chemotherapy backbone associated to the anti-EGFR, suggested that irinotecan-based or oxaliplatin-based regimens may not be equivalent with a possible advantage for the association of the anti-EGFR TT with the

A Pathological responses distribution depending on tumour responses evaluated by imagery RECIST categories

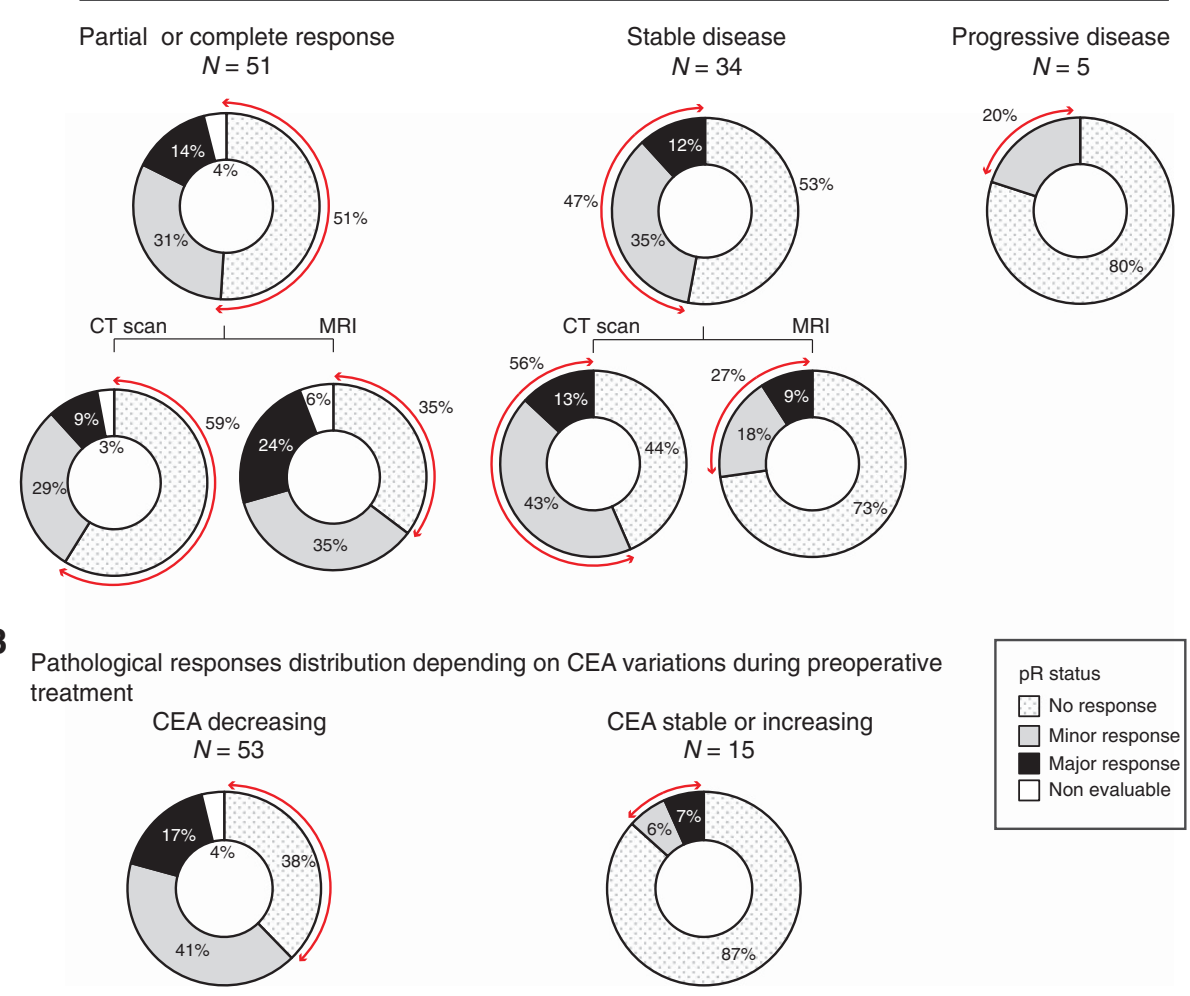

Figure 2. Concordances between radiologic tumour response assessment or serum CEA monitoring with pathological responses after preoperative treatment in $\mathrm{mCRC}$ patients. (A) Patients were allocated to the three categories defined by RECIST criteria for tumour response assessment based on radiology. The distribution of patients' pR status is reported (\%) within each of these categories. In a further analysis, RECIST evaluation based on CT Scan is distinguished from evaluation based on MRI. (B) The distribution of pR status among patients in whom CEA decrease during preoperative treatment vs those with a stable or increasing CEA is reported. Red arrows in (A) and (B) underline discordant results between different approaches to evaluate the tumour response. 
irinotecan chemotherapy backbone. But, the small number of patients treated with anti-EGFR TT in our cohort and the lack of information regarding the prevalence of NRAS gene mutations
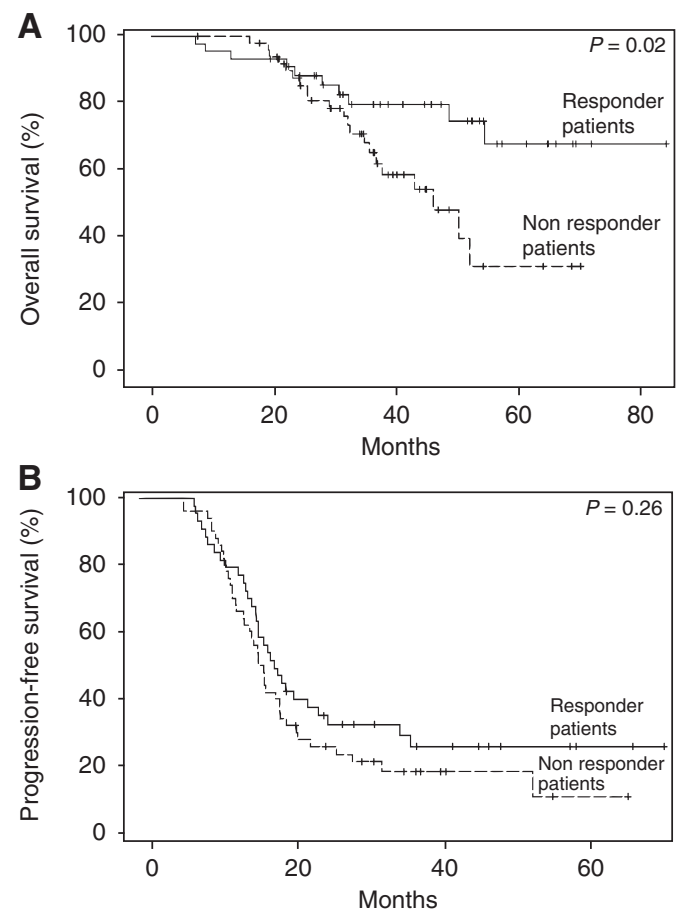

Figure 3. Overall survival (A) and progression-free survival (B) KaplanMeier curves according to $\mathrm{pR}$ status. among those patients, as they were treated before the recent extended RAS screening recommendations (Douillard et al, 2013), did not allow formal conclusions.

In the current study, $\mathrm{pR}$ to a preoperative treatment has been set in parallel with observed radiological tumour responses and concordances between these two approaches was weak. Among patients having a SD on imagery, almost half of them presented $\mathrm{pR}$ on their resected metastases. Moreover, more than 50\% of radiological responses were unconfirmed by the pathological approach, and these discordances were more frequent after CT scan evaluations than after MRI evaluations (Figure 2). This warrants the use of MRI when liver metastases resection is foreseen (Heijmen et al, 2015). Overall, these observations bring out the need to improve tumour responses evaluations procedures. The usage of metabolic imagery or the advent of new genetic tumour biomarkers offers hope for future improvements (Diehl et al, 2008; Siravegna et al, 2015).

The present study also revealed that $\mathrm{pR}$ was frequently heterogeneous in a single patient. This has been also described by Gervaz et al (2010) who reported better pRs in liver metastases than in the primary tumour in patients treated with chemotherapy before resection. Intrinsic tumour heterogeneity could explain these diverging therapeutic responses across different tumour sites. Over the past few years, huge advances in tumour genetics, and characterisation of the tumoural microenvironment, have clearly demonstrated that intra-tumour heterogeneity is a reality that should be considered when evaluating therapeutic tumour responses (Junttila and de Sauvage, 2013).

In conclusion, our retrospective analysis suggests that oxaliplatin or irinotecan-based-chemotherapies are not equivalent in terms of $\mathrm{pR}$, when they are partnered with an anti-angiogenics or EGFR inhibitors. In our study, anti-angiogenic/oxaliplatin-based regimens

Table 2. Univariate and multivariate analysis of factors potentially associated with overall survival in patients receiving preoperative chemotherapy before CRCM resection

\begin{tabular}{|c|c|c|c|c|}
\hline \multirow[b]{2}{*}{ Variables } & \multicolumn{2}{|c|}{ Univariate analysis } & \multicolumn{2}{|c|}{ Multivariate analysis } \\
\hline & $P$-value & HR & $P$-value & HR \\
\hline \multicolumn{5}{|l|}{ Patient demographics } \\
\hline $\begin{array}{l}\text { Sex (male/female) } \\
\text { Age }>70\end{array}$ & $\begin{array}{l}0.22 \\
0.76\end{array}$ & $\begin{array}{l}0.64 \\
1.12\end{array}$ & & \\
\hline \multicolumn{5}{|l|}{ Disease characteristics } \\
\hline $\begin{array}{l}\text { Synchronous/metachronous metastases } \\
\text { Primary tumour site: colon/rectum } \\
\text { Preoperative serum CEA level }\left(\mu \mathrm{I}^{-1}\right) \\
\text { Preoperative serum CEA change from base line (\%) }\end{array}$ & $\begin{array}{l}0.57 \\
0.94 \\
0.01 \\
0.09\end{array}$ & $\begin{array}{l}1.27 \\
1.02 \\
1.00 \\
0.99\end{array}$ & & \\
\hline \multicolumn{5}{|l|}{ Previous chemotherapy } \\
\hline Previous chemotherapy line(s) for metastatic disease & 0.66 & 1.21 & & \\
\hline \multicolumn{5}{|l|}{ Chemotherapy associated with metastases resection } \\
\hline $\begin{array}{l}\text { Preoperative chemotherapy }+ \text { anti-angiogenic compound } \\
\text { Preoperative chemotherapy }+ \text { anti-EGFR } \\
\text { Number of preoperative cycles } \\
\text { Postoperative chemotherapy } \\
\text { Total number of pre-postoperative cycles }\end{array}$ & $\begin{array}{l}0.29 \\
0.15 \\
0.20 \\
0.63 \\
0.14\end{array}$ & $\begin{array}{l}0.66 \\
0.41 \\
1.06 \\
1.83 \\
1.06\end{array}$ & & \\
\hline \multicolumn{5}{|l|}{ Surgery } \\
\hline $\begin{array}{l}\text { Portal vein embolization } \\
\text { Resection status R2 } \\
\text { Resection status R2 vs others }\end{array}$ & $\begin{array}{l}0.95 \\
0.01 \\
0.01\end{array}$ & $\begin{array}{l}1.02 \\
3.55 \\
3.56\end{array}$ & & \\
\hline \multicolumn{5}{|l|}{ Patient-related pathological response } \\
\hline $\begin{array}{l}\text { Worse TRG among resected metastases } \\
\text { Pathological responder status (TRG } \leqslant 3) / \text { non-responder }(T R G \geqslant 4)\end{array}$ & $\begin{array}{r}<0.01 \\
0.02\end{array}$ & $\begin{array}{l}1.8 \\
0.42\end{array}$ & $<0.01$ & 1.83 \\
\hline \multicolumn{5}{|l|}{ Imaging tumour response (RECIST) } \\
\hline Response (PR or CR)/no response (SD or PD) & 0.92 & 0.96 & & \\
\hline
\end{tabular}


and anti-EGFR/irinotecan-based regimens were associated with the highest $\mathrm{pR}$ rates. These exploratory observations must be validated by prospective randomised trials evaluating different chemotherapy partners that can be associated with anti-angiogenic or anti-EGFR TT before applying these findings in clinical practice.

\section{ACKNOWLEDGEMENTS}

The authors wish to thank Aileen Eiszele from A \& L Medical Communications for writing assistance.

\section{CONFLICT OF INTEREST}

The authors declare no conflict of interest.

\section{REFERENCES}

Abdalla E, Vauthey J, Ellis L (2004) Recurrence and outcomes following hepatic resection, radiofrequency ablation, and combined resection/ ablation for colorectal liver metastases. Ann Surg 239: 818-827.

Adam R, Delvart V, Pascal G, Valeanu A, Castaing D, Azoulay D, Giacchetti S, Paule B, Kunstlinger F, Ghémard O, Levi F, Bismuth $\mathrm{H}$ (2004a) Rescue surgery for unresectable colorectal liver metastases downstaged by chemotherapy: a model to predict long-term survival. Ann Surg 240: 644-658.

Adam R, Pascal G, Castaing D, Azoulay D, Delvart V, Paule B, Levi F, Bismuth H (2004b) Tumor progression while on chemotherapy: a contraindication to liver resection for multiple colorectal metastases? Ann Surg 240: 1052-1064.

Allen PJ, Kemeny N, Jarnagin W, DeMatteo R, Blumgart L, Fong Y (2003) Importance of response to neoadjuvant chemotherapy in patients undergoing resection of synchronous colorectal liver metastases. J Gastrointest Surg 7: 109-117.

Blazer D, Kishi Y, Maru DM, Kopetz S, Chun YS, Overman MJ, Fogelman D, Eng C, Chang DZ, Wang H, Zorzi D, Ribero D, Ellis LM, Glover KY, Wolff RA, Curley SA, Abdalla EK, Vauthey J-N (2008) Pathologic response to preoperative chemotherapy: a new outcome end point after resection of hepatic colorectal metastases. J Clin Oncol 26: 5344-5351.

Chibaudel B, Tournigand C, Bonnetain F, Hug de laurauze M, De Gramont A, Laurent-Puig P, Louvet C, André T, de Gramont A (2014) Strategic 1-multi-line therapy trial in unresectable wild-type RAS metastatic colorectal cancer: A gercor randomized open-label phase III study. $J$ Clin Oncol 32(suppl): 5s; abstr TPS3648.

Diehl F, Schmidt K, Choti MA, Romans K, Goodman S, Li M, Thornton K, Agrawal N, Sokoll L, Szabo SA, Kinzler KW, Vogelstein B, Diaz LA (2008) Circulating mutant DNA to assess tumor dynamics. Nat Med 14: 985-990.

Douillard J-Y, Oliner KS, Siena S, Tabernero J, Burkes R, Barugel M, Humblet Y, Bodoky G, Cunningham D, Jassem J, Rivera F, Kocákova I, Ruff P, Błasińska-Morawiec M, Šmakal M, Canon JL, Rother M, Williams R, Rong A, Wiezorek J, Sidhu R, Patterson SD (2013) Panitumumab-FOLFOX4 treatment and RAS mutations in colorectal cancer. N Engl J Med 369: 1023-1034.

Edge S, Byrd D, Compton C, Fritz A, Greene F, Trotti A (2010) AJCC Cancer Staging Manual. Springer.

Eisenhauer E, Therasse P, Bogaerts J, Schwartz L, Sargent D, Ford R, Dancey J, Arbuck S, Gwyther S, Mooney M (2009) New response evaluation criteria in solid tumours: revised RECIST guideline (version 1.1). Eur J Cancer 45: 228-247.

Gervaz P, Rubbia-Brandt L, Andres A, Majno P, Roth A, Morel P, Mentha G (2010) Neoadjuvant chemotherapy in patients with stage IV colorectal cancer: a comparison of histological response in liver metastases, primary tumors, and regional lymph nodes. Ann Surg Oncol 17: 2714-2719.

Heijmen L, ter Voert EEGW, Oyen WJG, Punt CJA, van Spronsen DJ, Heerschap A, de Geus-Oei L-F, van Laarhoven HWM (2015)
Multimodality imaging to predict response to systemic treatment in patients with advanced colorectal cancer. PLoS One 10: e0120823.

Heinemann V, Modest D, Fischer von Weikersthal L, Decker T, Kiani A, Vehling-Kaiser U, Al-Batran S-E, Heintges T, Lerchenmuller C, Kahl C, Seipelt G, Kullmann F, Stauch M, Scheithauer W, Held S, Giessen C, Mohler M, Jagenburg A, Stintzing S (2014a) Independent radiological evaluation of objective response early tumor shrinkage, and depth of response in fire-3 (AIO KRK-0306). Ann Oncol 25: iil17.

Heinemann V, von Weikersthal LF, Decker T, Kiani A, Vehling-Kaiser U, Al-Batran S-E, Heintges T, Lerchenmüller C, Kahl C, Seipelt G, Kullmann F, Stauch M, Scheithauer W, Hielscher J, Scholz M, Müller S, Link H, Niederle N, Rost A, Höffkes H-G, Moehler M, Lindig RU, Modest DP, Rossius L, Kirchner T, Jung A, Stintzing S (2014b) FOLFIRI plus cetuximab versus FOLFIRI plus bevacizumab as first-line treatment for patients with metastatic colorectal cancer (FIRE-3): a randomised, open-label, phase 3 trial. Lancet Oncol 15(10): 1065-1075.

Junttila MR, de Sauvage FJ (2013) Influence of tumour micro-environment heterogeneity on therapeutic response. Nature 501: 346-354.

Nordlinger B, Sorbye H, Glimelius B, Poston GJ, Schlag PM, Rougier P, Bechstein WO, Primrose JN, Walpole ET, Finch-Jones M, Jaeck D, Mirza D, Parks RW, Collette L, Praet M, Bethe U, Van Cutsem E, Scheithauer W, Gruenberger T (2008) Perioperative chemotherapy with FOLFOX4 and surgery versus surgery alone for resectable liver metastases from colorectal cancer (EORTC Intergroup trial 40983): a randomised controlled trial. Lancet 371: 1007-1016.

Nordlinger B, Sorbye H, Glimelius B, Poston GJ, Schlag PM, Rougier P, Bechstein WO, Primrose JN, Walpole ET, Finch-Jones M, Jaeck D, Mirza D, Parks RW, Mauer M, Tanis E, Van Cutsem E, Scheithauer W, Gruenberger T (2013) Perioperative FOLFOX4 chemotherapy and surgery versus surgery alone for resectable liver metastases from colorectal cancer (EORTC 40983): long-term results of a randomised, controlled, phase 3 trial. Lancet Oncol 14: 1208-1215.

Pietrantonio F, Mazzaferro V, Miceli R, Cotsoglou C, Melotti F, Fanetti G, Perrone F, Biondani P, Muscarà C, Di Bartolomeo M, Coppa J, Maggi C, Milione M, Tamborini E, de Braud F (2015) Pathological response after neoadjuvant bevacizumab- or cetuximab-based chemotherapy in resected colorectal cancer liver metastases. Med Oncol 32(7): 182.

Rubbia-Brandt L, Giostra E, Brezault C, Roth AD, Andres A, Audard V, Sartoretti P, Dousset B, Majno PE, Soubrane O, Chaussade S, Mentha G, Terris B (2007) Importance of histological tumor response assessment in predicting the outcome in patients with colorectal liver metastases treated with neo-adjuvant chemotherapy followed by liver surgery. Ann Oncol 18: 299-304.

Schwartzberg LS, Rivera F, Karthaus M, Fasola G, Canon J-L, Hecht JR, Yu H, Oliner KS, Go WY (2014) PEAK: a randomized, multicenter phase II study of panitumumab plus modified fluorouracil, leucovorin, and oxaliplatin (mFOLFOX6) or bevacizumab plus mFOLFOX6 in patients with previously untreated, unresectable, wild-type KRAS Exon 2 metastatic colorectal. J Clin Oncol 32: 2240-2247.

Siravegna G, Mussolin B, Buscarino M, Corti G, Cassingena A, Crisafulli G, Ponzetti A, Cremolini C, Amatu A, Lauricella C, Lamba S, Hobor S, Avallone A, Valtorta E, Rospo G, Medico E, Motta V, Antoniotti C, Tatangelo F, Bellosillo B, Veronese S, Budillon A, Montagut C, Racca P, Marsoni S, Falcone A, Corcoran RB, Di Nicolantonio F, Loupakis F, Siena S, Sartore-Bianchi A, Bardelli A (2015) Clonal evolution and resistance to EGFR blockade in the blood of colorectal cancer patients. Nat Med 21(7): 795-801.

Stremitzer S, Stift J, Singh J, Starlinger P, Gruenberger B, Tamandl D, Gruenberger T (2015) Histological response, pattern of tumor destruction and clinical outcome after neoadjuvant chemotherapy including bevacizumab or cetuximab in patients undergoing liver resection for colorectal liver metastases. Eur J Surg Oncol 41(7): 868-874.

This work is published under the standard license to publish agreement. After 12 months the work will become freely available and the license terms will switch to a Creative Commons AttributionNonCommercial-Share Alike 4.0 Unported License.

Supplementary Information accompanies this paper on British Journal of Cancer website (http://www.nature.com/bjc) 